\title{
IMPLICACÕES DO SUBPROJETO PIBID INTERDISCIPLINAAR PARA A FORMAÇÃO INICIAL EM EDUCAÇÃO FÍSICA
}

DOI: 105902/0102830817944

Data de Submissão: 08/05/2015

Data de Aprovação: 11/02/2016

\author{
Janaine Welter \\ Universidade Federal de Santa Maria \\ janainewelter@gmail.com \\ Rosalvo Luis Sawitzki \\ Universidade Federal de Santa Maria \\ rosalvols@hotmail.com
}

RESUMO: O objetivo deste estudo consiste em analisar as implicações do subprojeto PIBID "Organização do Trabalho Pedagógico do professor de Educação Física e da Pedagogia nos Anos Iniciais do Ensino Fundamental" para a formação inicial em Educação Física. A metodologia é caracterizada como um estudo de caso. Averiguou-se que a proposta interdisciplinar e a experiência foram os motivos que levaram os bolsistas a ingressarem no subprojeto. $O$ trabalho pedagógico no subprojetoé caracterizado por momentos de docência nas escolas, reuniões pedagógicas e grupo de estudo. Os bolsistas, no que refere-se à formação inicial, relatam apenas contribuições, não identificando elementos negativos.

Palavras-chave: Educação física; Escola; Educação. 


\section{Considerações iniciais}

O Programa Institucional de Bolsa de Iniciação à Docência surgiu em 2007, tendo como objetivo incentivar a formação de professores para a Educação Básica, além de inserir os acadêmicos de licenciaturas no cotidiano de escolas da rede pública de educação, proporcionando-Ihes oportunidades de criação e participação em experiências metodológicas e de práticas docentes de caráter inovador e interdisciplinar.

As universidades, na formação de professores, necessitam fomentar a formação inicial por meio de programas que possibilitem a pesquisa no âmbito da docência, levando em consideração o dia a dia das escolas com a efetiva participação do professor em atuação (SILVA; PIRES, 2006). Desse modo, o PIBID procura fazer esta interlocução entre a escola e a universidade, como um momento que pode vir a repercutir na formação inicial.

Este estudo refere-se ao subprojeto PIBID “Organização do Trabalho Pedagógico do professor de Educação Física e da Pedagogia nos Anos Iniciais do Ensino Fundamental". O subprojeto PIBID em questão está sendo desenvolvido em quatro (4) escolas da rede pública no munícipio de Santa Maria/RS. Os integrantes deste subprojeto são quatro (4) professores das escolas, vinte e um (21) bolsistas, sendo que destes, treze (13) são do curso de Educação Física e oito (8) do curso de Pedagogia.

O PIBID possibilita a compreensão de que a docência, "[...] entendida como trabalho pedagógico, é, portanto, a identidade profissional do professor de Educação Física." (TAFFAREL et al., 2006, p.161). Dessa forma, esta área de conhecimento é compreendida a partir do trabalho pedagógico e, em seu viés docente, configurase como a identidade profissional.

O objetivo deste artigo consiste em analisar as implicações do subprojeto PIBID "Organização do Trabalho Pedagógico do professor de Educação Física e da Pedagogia nos Anos Iniciais do Ensino Fundamental" para a formação inicial 
em Educação Física, do Centro de Educação Física e Desportos, da Universidade Federal de Santa Maria -CEFD/UFSM, tendo-se como objetivos específicos: verificar os motivos/expectativas de ingresso no subprojeto; caracterizar o trabalho pedagógico desenvolvido pelos bolsistas em Educação Física; verificar os impactos do subprojeto para a formação inicial em Educação Física.

Este estudo surge a partir do envolvimento com o PIBID, o qual desperta e instiga a pesquisar. Além disso, o estudo se justifica pelo fato de o PIBID ser uma política educacional recente, carecendo de aprofundamento teórico acerca do trabalho pedagógico e suas implicações para a formação de professores. Desse modo, o estudo visa contribuir para a produção de conhecimento sobre o trabalho pedagógico e as implicações para a formação de professores do CEFD/UFSM.

Compartilha-se a ideia de Taffarel et al. (2006) quando afirma que a Educação Física pode ser compreendida por meio do trabalho pedagógico, tendo como área de conhecimento a Cultura Corporal. Nesse momento, procura-se caracterizar o trabalho pedagógico como a base norteadora e o suporte teórico deste artigo, correlacionando com autores que defendem esse pressuposto.

Frizzo (2008, p.159) evidencia que o trabalho pedagógico diz respeito a "[...] uma noção ampliada do trabalho desenvolvido pelo professor na escola e de suas possibilidades de articulação entre a macroestrutura sociopolítica e o cotidiano da docência nos espaços escolares". Desse modo, o trabalho pedagógico não se restringe apenas a atuação do professor perante sua aula, sendo que este pode ser condicionado pelas determinações sociais e políticas.

Freitas (2004, p. 100) afirma que o trabalho pedagógico deve estar relacionado à produção do conhecimento mediado pela relação entre teoria e prática. Sendo assim, "[...] a prática refletindo-se na forma de teoria que é devolvida à prática, num circuito indissociável e interminável de aprimoramento”. Nesse sentido, percebe-se o valor que a práxis assume como elemento norteador do trabalho pedagógico do professor. De acordo com Ribas e Ferreira (2014),o trabalho do professor não é somente prático, pois considerá-lo deste modorestringe a atuação 
e as suas implicações;nesse viés, o trabalho pedagógico pode ser considerado uma práxis pedagógica.

Nas palavras de Frizzo (2008a) o trabalho pedagógico:

[...] é uma prática social que atua na configuração da existência humana individual e grupal para realizar nos sujeitos humanos as características de seres humanos. Essa prática social é munida de forma e conteúdo, expressando dentro das suas possibilidades objetivas as determinações políticas e ideológicas dominantes em uma sociedade. Evidencia-se que essas determinações assumem uma ordem geral que correspondem aos movimentos da economia, tanto no sentido do modo de produção quanto das forças produtivas. A escola, espaço institucional de formação humana, cumpre determinações desta prática social e o trabalho pedagógico procura dar conta dessa tarefa (FRIZZO, 2008a, p.163).

Deste modo, o trabalho pedagógico está diretamente relacionada a docência e a todos os elementos que o determinam, tais como as questões de ordem social e política que acabam influenciando o processo educativo como um todo. Por isso, pensar em trabalho pedagógico é ampliar e inter-relacionar todos os elementos conjuntamente, ou seja, considerar, por exemplo, o planejamento, as condições de trabalho, a realidade social da escola e alunos, os conteúdos, a organização social como constituintes do trabalho pedagógico e determinantes para o desenvolvimento da aula.

\section{Pressupostos Metodológicos}

A metodologia a ser utilizada nesse trabalho é caracterizada como um estudo de caso, que procura analisar as particularidades de um fenômeno (LÜDKE; ANDRÉ, 1986). Segundo Gil (2010), o estudo de caso procura aprofundar um objeto de estudo com a finalidade de conhecer de forma detalhada suas características. Neste caso, refere-se ao subprojeto PIBID “Organização do Trabalho Pedagógico do professor de Educação Física e da Pedagogia nos Anos Iniciais do Ensino Fundamental".

Para a coleta das informações, utilizou-se questionário com perguntas abertas, no qual os sujeitos da pesquisa devem responder, não sendo necessária a presença 
do pesquisador (MARCONI; LAKATOS, 2010). Os sujeitos desta pesquisa são bolsistas de iniciação à docência de Educação Física, participantes do subprojeto. Assim, foram entregues doze (12) questionários, sendo que retornaram dez (10). A amostra dos sujeitos desta pesquisa se caracteriza preferencialmente pelos bolsistas de Educação Física que já estava há pelo menos dois (2) anos no curso e há um semestre no subprojeto.

Para a coleta dos dados, inicialmente foi estabelecido um contato prévio com o público alvo do estudo, a fim de apresentar a pesquisa, seus objetivos e metodologia a serem realizados. Após esse contato, os sujeitos optam em participar ou não da pesquisa. Aqueles que aceitarem participar assinaram o Termo de Compromisso Livre e Esclarecido (TCLE) para autorizar a sua participação no estudo. Este trabalho foi aprovado no Comitê de Ética sob nº 33985014.5.0000.5346.

O procedimento de análise dos dados utilizados nesta pesquisa foi a análise de conteúdo. Segundo Bardin (2006) apresenta as seguintes fases: $1^{\circ}$ ) préanálise - ocorre a sistematização das ideias nas seguintes etapas: a) leitura flutuante, o contato inicial com o conteúdo a ser investigado; b) escolha dos documentos, demarcação do que será analisado; c) formulação de hipóteses e objetivos; d) referenciação dos índices e elaboração dos indicadores, escolha dos indicadores a partir de recortes do texto; $2^{\circ}$ ) exploração do material a partir de sistemas de codificação, classificação e categorização - neste estudo refere-se a delimitação objetivos específicos (motivo de ingresso no PIBID, trabalho pedagógico, formação inicial); $3^{\circ}$ ) tratamento dos resultados, inferência e interpretação - pode ser considerado o momento da intuição, da análise reflexiva e crítica.

O questionário apresentou três blocos de perguntas. O primeiro, relacionado ao PIBID, o segundo, referente ao trabalho pedagógico desenvolvido pelos bolsistas; e, por último, as implicações do subprojeto na formação inicial. 


\section{Discussão e análise dos resultados}

No primeiro bloco de perguntas, procurou-se identificar o interesse dos bolsistas em adentrar no subprojeto. Percebe-se, com base nos dados, que a maioria ingressou no subprojeto por este apresentar uma proposta interdisciplinar e também com intuito de adquirir experiências, como explicitado na fala do sujeito 2:

O que me levou a ingressar no PIBID foi a necessidade de me aproximar mais do contexto escolar, obter mais conhecimento sobre o saber e fazer do professor nos anos iniciais. E também pela necessidade de compreender a importância do trabalho interdisciplinar e como realizáIo (SUJEITO 2).

Nota-se o interesse dos bolsistas na inserção escolar e tambémem compreender como se constitui a organização do trabalho pedagógico do professor nos anos iniciais. Bracht(1999) enuncia a necessidade de as aulas de Educação Física não se restringirem apenas ao saber praticar, mas também o saber sobre o fazer corporal. Nesse viés, o aluno deve não apenas praticar, como também saber falar a respeito.

De acordo com Souza (2003, p. 135), "A interdisciplinaridade, em sentido amplo, constitui uma perspectiva que visa superar a fragmentação do saber presente no sistema de ensino formal". Nesse sentido, a proposta interdisciplinar procura abranger uma ou várias áreas de conhecimento; dessa forma, determinado conteúdo ou objeto procura ser compreendido em sua totalidade.

No segundo bloco, procurou-se identificar como está estruturada a organização do subprojeto, de modo a caracterizar o trabalho pedagógico desenvolvido pelos bolsistas. Parte-se de questões relacionadas à inserção dos bolsistas no espaço escolar, como acontecem às intervenções pedagógicas nas escolas, como é desenvolvido o planejamento.

Cada escola participante apresenta bolsistas de Educação Física e Pedagogia, os quais realizam atividades na escola duas vezes na semana, ou cumprindo uma carga horária de 8 horas, de acordo com a proposta estabelecida pelo programa. 
Tambémrealizam reuniões pedagógicas nas escolas, com a participação dosbolsistas e supervisores, além do encontro semanal ou quinzenal de todos os envolvidos no subprojeto (coordenador, supervisores, bolsistas). Todos os bolsistas salientaram uma boa relação entre os envolvidos no subprojeto. As escolas participantes do subprojeto são da rede estadual e apresentam características específicas. Segundo os bolsistas, a inserção no ambiente escolar teve a receptividade da escola (equipe diretiva, professores) e, num primeiro momento,esses bolsistas realizaram um diagnóstico da realidade, por meio da observação de aulas dos professores unidocentes.

No que se refere às intervenções nas escolas, cada grupo apresentou sua organização; por isso, a iniciação à docência é realizada de forma individual ou em dupla (Educação Física e Pedagogia). Nota-se que isso aconteceu pela liberdade que os bolsistas têm em relação a sua organização, devendo irao encontro das necessidades e características das escolas. O coordenador do subprojeto, num primeiro momento, possibilitou que cada escola tivesse liberdade para organizar as ações pedagógicas no contexto escolar de acordo com o grupo envolvido e as especificidades das escolas.

Vale salientar que a escola, enquanto uma instituição social, não é neutra, ou seja, a organização do trabalho pedagógico da escola está atrelada a uma organização social (FREITAS, 2004). De acordo com Frizzo (2008b) para compreender a escola é necessário entender a realidade em que a mesma está inserida, sendo que o ponto de partida éa relação estabelecida entre o trabalho pedagógico e a prática social engendrada por uma sociedade capitalista.

[...] Também a escola tem conteúdos, métodos e objetivos. Chega-se assim, aos próprios objetivos da organização do trabalho pedagógico na escola. O conteúdo e a forma da escola (inclusive seus métodos didáticos) estão modulados pela função da escola, na sociedade capitalista- ainda que não de forma mecânica e inevitável (FREITAS, 2004, p. 59).

Nesse sentido, a sociedade pode ser um condicionante para a organização do trabalho pedagógico da escola que vai influenciar o trabalho pedagógico dos 
professores, consequentemente, o trabalho desenvolvido pelos bolsistas na escola.

O planejamento no subprojeto é desenvolvido de várias maneiras; possivelmente, cada escola estabeleceu uma maneira que acreditou ser mais coerente com a proposta pedagógica da escola e do subprojeto PIBID, assim como a concepçãopedagógica dos bolsistas. Por isso, evidenciamos as seguintes descrições abaixo:

Planejamento conforme a necessidade das turmas e em consonância com os conteúdos desenvolvidos pelas professoras unidocentes(SUJEITO 1).

[...] inicialmente foi realizado um diagnóstico geral dos alunos, passando para os testes motores aplicados e a partir daí, foram planejadas aulas em busca de melhoras na capacidade motora que apresentaram maus resultados (SUJEITO 3).

[...] os planejamentos são feitos por mim, mesmo sendo um projeto interdisciplinar e ministrar as aulas com uma colega da pedagogia, estão acontecendo apenas aulas de educação física. Critérios: faixa etária da turma, principais dificuldades dos alunos (SUJEITO 4).

Percebe-se que os bolsistas utilizaram diferentes critérios para o planejamento das práticas de ensino, sejam eles aspectos sociais, sejam motores, cognitivos. 0 planejamento, para Libâneo (1994), consiste na tarefa de o professor possibilitar a organização e coordenação do docente frente às atividades a serem desenvolvidas, bem como serve, também, como um momento de avaliação docente frente à prática pedagógica.

Os bolsistas salientam algumas circunstâncias em relação ao trabalho interdisciplinar, apontando-o como uma dificuldade. Nota-se que em uma escola o planejamento é realizado por todos a partir de uma temática; os bolsistas de Educação Física planejam de acordo com os conteúdos de sua área, e os de Pedagogia também (BOLSISTA 1, 2). Bem como se evidenciounos questionários dos bolsistas 4 e 5, o planejamento está sendo realizado apenas pelo bolsista de Educação Física, percebendo-se que este aponta esse fato como uma dificuldade encontrada até o momento. 
O trabalho com a colega da pedagogia que dá aula junto comigo não é muito bom. Há pouca comunicação e raramente ela ajuda no planejamento das aulas (SUJEITO 4).

Nota-se a dificuldade que alguns bolsistas apresentam em relação à interdisciplinaridade. Para Frigoto (2008a), a interdisciplinaridade é, ao mesmo tempo, uma necessidade e um problema, como relatado neste trecho:

O processo de conhecimento social vem então marcado pelos interesses, concepções e condições de classe do investigador. O conhecimento não tem como ser produzido de forma neutra tendo em vista que as relações que ele tenta apreender não são neutras. É justamente neste âmbito que percebemos que a interdisciplinaridade na produção do conhecimento nos é uma necessidade imperativa, mas nos é também um problema que está plotado na materialidade das relações capitalistas de produção da existência. Sem penetrarmos na aridez desta materialidade a questão do debate da interdisciplinaridade fica num limbo sem pecado e sem prazer limbo da discussão lógico-formal, discursiva (FRIGOTO, 2008, p. 46-47, grifos do autor).

Nesse viés, torna-se necessário entender a totalidade de um fenômeno, tudo que pode interferir, na medida em que também se torna problema complexo. Por isso, o autor evidencia que é necessário analisar os fatores que a determinam e que interferem no fato estudado (FRIGOTTO, 2008).

Frigoto (2008, p.59) expõe que a principal dificuldade do trabalho interdisciplinar está relacionada a "[...] uma formação fragmentária, positivista e metafísica do educador e de outra nas condições de trabalho (divisão e organização) a que está submetido." Percebe-se, desse modo, que a formação de professores tem papel neste processo. Segundo Frizzo (2008a) para problematizar a formação de professores e o trabalho pedagógico é fundamental entender o sistema de produção capitalista que delibera um plano de mundialização da educação que é caracterizada por duas categorias: disciplinamento (manutenção da sociedade) e empregabilidade (preparação de mão-de-obra).

No último bloco, as questões estão relacionadas à formação inicial, com intuito de averiguar as repercussões do subprojeto no processo de formação acadêmica dos bolsistas. 
Fazendo uma análise sobre a formação de Educação Física, penso que existe uma distância considerável entre as disciplinas e as escolas. Logo, com o PIBID esta distância diminui, pois a possibilidade de adquirir experiências é muito importante (SUJEITO 7).

Com base nestes elementos, Taffarel (1996) aponta algumas problemáticas apresentadas nos cursos de formação de professores em Educação Física, dentre os quais evidenciamos: fragmentação do conhecimento, currículo, separação entre teoria e prática. Por isso, talvez os bolsistassalientem a necessidade de participar de projetos de extensão, ensino e pesquisa para complementar sua formação - dentre esses projetos, o PIBID.Também nota-se que esses bolsistasrelatam contribuições para sua formação, tais comoa relação entre teoria e prática, conhecimento do cotidiano escolar, experiência adquirida com o subprojeto e importância do planejamento.

No que diz respeito ao trabalho pedagógico no subprojeto em relação às práticas de ensino, os bolsistas evidenciaram que as aprendizagens no PIBID foram mais significativas.

Sim, embora estando na escola não nos sentimos parte dela durante os estágios, já no PIBID, fazemos parte daquele contexto, somos realmente tratados como futuros professores. Pois planejamos juntamente com os professores, além de termos a possibilidade de construir nossas ações, organizar nossas aulas da maneira que julgamos ser a melhor para a formação de nossos alunos, podemos criar, modificar, refletir sobre aquilo que fazemos (SUJEITO 2).

Nesse relato, percebe-se que o PIBID é algo muito valorizado pelosbolsistas, pelas significativas contribuições quando comparado às práticas de ensino. Não temos a intenção de criticar os estágios; acreditamos que são também importantes para a formação. Os bolsistas não relatam se o trabalho pedagógico é problematizado na formação inicial.

\section{Considerações finais}

O trabalho pedagógico não se restringe à aula, refere-se a tudo que o professor realiza, abrangendo, assim, condicionantes sociais, as quais podem 
repercutir no trabalho do professor. Assim, fatores sociais e histórico-culturais podem influenciar o trabalho pedagógico, consequentemente a organização do trabalho pedagógico do bolsista.

Desse modo, a formação de professores deve oferecer subsídios para o trabalho pedagógico do professor. O PIBID, como política educacional, visa também contribuir no processo de formação docente, de modo a possibilitar a iniciação à docência nos cursos de licenciatura.

Taffarel (2010) defende que o trabalho pedagógico deve ser a base dos cursos de formação inicial em Educação Física. Entende-se por formação inicial o momento a partir do qual ocorre ingresso no curso de nível superior. De acordo com Sanches (2007), a experiência que o aluno adquire antes de entrar ou dentro do curso de graduação em relação à docência é relevante para sua formação, possibilitando a estes subsídios quando comparados a quem não teve experiências. Nota-se, dessa maneira, que o subprojeto pode ser um diferencial na formação dos acadêmicos que tiverem a oportunidade de nele ingressar.

Com base na análise dos questionários, averiguou-se que os motivos que levaram os bolsistas a ingressarem no subprojeto - a proposta interdisciplinare a necessidade de adquirir experiências no contexto escolar - em virtude de o curso de formação inicial apresentar lacunas nesses aspectos, conforme apontados pelos bolsistas.

O trabalho pedagógico no subprojeto é caracterizado por momentos de docência, reuniões pedagógicas nas escolas e o grupo de estudo. O planejamento é um momento de relevância no subprojeto, apesar de alguns bolsistas relatarem dificuldades em virtude do trabalho com os bolsistas de Pedagogia. Isso está relacionado à dificuldade de concretização de uma proposta interdisciplinar, devido, principalmente, à fragmentação do conhecimento. No entanto, as dificuldades também são importantes para que ocorra a aprendizagem.

Os bolsistas, no que se refere à formação inicial, relatam apenas contribuições, não identificam no subprojeto elementos negativos. As contribuições elencadas 
foram poucas, centradas, principalmente, em apontamentos mais frequentes: o conhecimento da realidade escolar e experiência; aproximação entre teoria e prática; importância do planejamento. Quando comparado às disciplinas de práticas de ensino, relatam que o subprojeto PIBID possibilitou maiores aprendizados. Nesse sentido, é necessário repensar os estágios na formação inicial e as possíveis causas disso, no intuito de aprimorar o processo de formação de professores.

Ratifica-se a necessidade de o PIBID continuar sendo tema de estudos, com o propósito de analisar o trabalho pedagógico que vem sendo desenvolvido no programa, pois os bolsistas apontam contribuições significativas para a formação inicial e também por este constituir-se como política educacional.

\section{Referências}

BARDIN, L. Análise de conteúdo (L. de A. Rego \& A. Pinheiro, Trads.). Lisboa: Edições 70, 2006.

BRACHT, V. A constituição das teorias pedagógicas da Educação Física. CadernosCede, ano XIX, n. 48, 1999.

FREITAS, L. C. Crítica da Organização do trabalho pedagógico e da Didática. Campinas, SP: Papirus, 2004.

FRIGOTO, G. O enfoque da dialética materialista histórica na pesquisa educacional. In: FAZENDA, I. C. A. (org.). Metodologia da pesquisa educacional. 12. ed. São Paulo: Cortez, 2010.

A interdisciplinaridade como necessidade e como problema nas ciências sociais. Revista do Centro de Educação e Letras, Foz do Iguaçu, Paraná, v.10, n.1, p.41-62, 2008. Disponível em: <http://erevista.unioeste.br/index. php/ideacao/article/view/4143/3188>. Acesso em 10 nov. 2013. 
FRIZZO, G. O trabalho pedagógico como referência para a pesquisa em Educação Física. Pensar a prática, Góias, v. 11, n. 2, p. 159-167, maio/ago, 2008a. Disponível:<http://www.revistas.ufg.br/index.php/fef/article/viewFile/3535/4097 >. Acesso nov. 2014.

FRIZZO, G. A produtividade da Educação Física improdutiva. Movimento, Porto Alegre, v. 14, n. 03, p. 209-232, setembro/dezembro de 2008b . Disponível:<http:// www.seer.ufrgs.br/Movimento/article/view/2591 >. Acesso ago. 2014.

GIL, Antonio Carlos. Métodos e Técnicas de Pesquisa Social. 6 ed. São Paulo: Atlas, 2010.

LIBÂNEO, J.C. Didática. São Paulo: Cortez, 1994.

LÜDKE, M.; ÀNDRE, M. E. D. A. Pesquisa em Educação; abordagens qualitativas. São Paulo: EPU, 1986.

MARCONI, M. A.; LAKATOS, E. M. Técnicas de pesquisa: planejamento e execução de pesquisas, amostragens e técnicas de pesquisa, elaboração, análise e interpretação de dados. 7 ed. São Paulo: Atlas, 2010.

RIBAS, J. F. M.; FERREIRA,L. S. Trabalho de professores na escola como práxis pedagógica. Movimento: Porto Alegre, v. 20, n. 01, p. 125-143, jan/mar de 2014. Disponível em:<http://www.seer.ufrgs.br/Movimento/article/view/40235>. Acesso em: nov. 2014.

SANCHES, J. G. Saberes docentes e formação profissional: o exercício imaturo da docência. Revista Científica da Faminas, v. 3, n. 1, jan-abr de 2007. Disponível 
em: <http://www.faminas.edu.br/upload/downloads/200910151752422295.pdf>. Acesso em:13 maio 2014.

SILVA, M. R; PIRES, G. L. Formação Inicial e Capacitação em serviço de professores de Educação Física: duas faces do mesmo desafio. Revista Motrivivência, Ano XVIII, n²6, p 9-14, junho/2006. Disponível em:<https://periodicos.ufsc.br/index. php/motrivivencia/article/view/677/1867>. Acesso em:

27 jun. 2014.

SOUZA, E. F. M. Interdisciplinaridade. Vértices. Rio de Janeiro, ano 5, n. 3, set/ dez. 2003. Disponível em:<http://essentiaeditora.iff.edu.br/index.php/vertices/ article/view/125>. Acesso em: ago. 2014.

TAFFAREL, C. Z. et al.Formação de Professores de Educação física: estratégia e táticas. Motrivivência, ano xviii, n. 26, p. 89-111 jun./2006. Disponível em:<https:// periodicos.ufsc.br/index.php/motrivivencia/article/view/681>. Acesso em: out. 2014.

TAFFAREL, C. Do Trabalho em geral ao Trabalho Pedagógico: contribuição ao debate sobre o trabalho pedagógico na educação física. Motrivivência, Ano XXII, n. 35, p. 18-40 Dez./2010. Disponível em:<https://periodicos.ufsc.br/index. php/motrivivencia/article/view/21758042.2010v22n35p18/18082>. Acesso em: out. 2014. 


\title{
IMPLICATIONS OF SUBPROJECT PIBID INTERDISCIPLINAR INITIAL TRAINING IN PHYSICAL EDUCATION
}

\begin{abstract}
The objectiveofthisstudyistoanalyzetheimplicationsofthesubproject PIBID “Organização do Trabalho Pedagógico do professor de Educação Física e da Pedagogia nos Anos Iniciais do Ensino Fundamental for initial training in PhysicalEducation. The methodology is characterized as a case study. Based on the analysis of the questionnaires, it was established that the interdisciplinary approach and the experience were the reasons that led scholars to join the subproject. The educational work in the subproject is characterized by moments of teaching in schools, educational meetings and study group. Fellows, as concerns the initial training, report only contributions, identifying negative elements. It is necessary to develop more studies about the pedagogical work in PIBID subprojects.
\end{abstract}

Keywords: Physical education; School; Education.

\section{IMPLICACIONES DE SUBPROYECTO PIBID INTERDISCIPLINAR FORMACIÓN INICIAL EN EDUCACIÓN FÍSICA}

Resumen: Este estúdio tiene como objetivo analizarlasimplicacionesdelsubproyec to PIBID “Organização do Trabalho Pedagógico do professor de Educação Física e da Pedagogia nos Anos Iniciais do Ensino Fundamental" para laformaciónenEducación Física. La metodología se caracteriza como un estudio de caso. A partir del análisis de los cuestionarios, se estableció que el enfoque interdisciplinario y la experiencia fueron las razones que llevaron a participa del subproyecto. El trabajo pedagógico en el subproyecto se caracteriza por momentos de enseñanza en las escuelas, reuniones educativas y grupo de estudio. Los estudiantes se refiere a la formación inicial, el informe solamente sus contribuciones, no se identifico elementos negativos. Es necesario desarrollar más estudios sobre el trabajo pedagógico en subproyectos PIBID

Palabras-clave: Educación Física; Escuela; Enducación. 